\title{
Dye-Sensitized Downconversion
}

\author{
Zijun Wang and Andries Meijerink* \\ Condensed Matter and Interfaces, Debye Institute for Nanomaterials Science, Utrecht University, Princetonplein 1, 3584 CC Utrecht, \\ Netherlands
}

\section{Supporting Information}

ABSTRACT: Splitting one high-energy photon into two lower energy photons through downconversion has been demonstrated for a variety of combinations of rare earth (RE) ions. However, the low absorption cross section of $\mathrm{RE}^{3+} 4 \mathrm{f}-4 \mathrm{f}$ transitions hampers practical application. Therefore, enhancing the absorption by sensitization is crucial. We demonstrate efficient dye-sensitized downconversion using a strong blue/UV absorbing Coumarin dye to sensitize downconversion of the $\operatorname{Pr}^{3+}-\mathrm{Yb}^{3+}$ couple in $\mathrm{NaYF}_{4}$ nanocrystals (NCs). Luminescence spectra and lifetime measurements reveal Förster resonant energy transfer (FRET) from Coumarin to $\mathrm{Pr}^{3+}$ in $\mathrm{NaYF}_{4}: \mathrm{Pr}^{3+} \mathrm{Yb}^{3+} \mathrm{NCs}$, followed by downconversion, resulting in

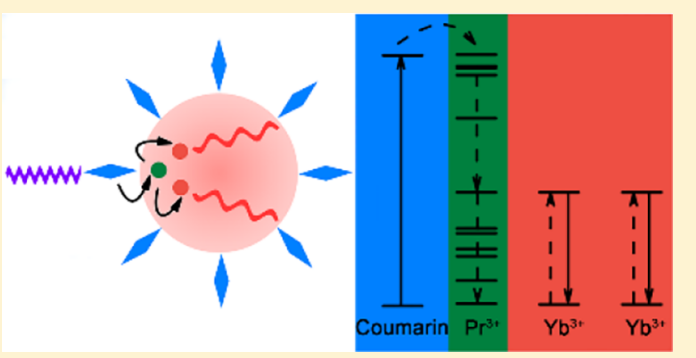

$\mathrm{Yb}^{3+}$ IR emission with $\sim 30$ times enhancement. The present study demonstrates the feasibility of dye-sensitized downconversion as a promising strategy to engineer strongly absorbing downconversion NCs to enhance the efficiency of photovoltaic cells.

$\mathrm{D}$ ownconversion, also known as quantum cutting, is a process in which one high-energy photon is split into two low-energy photons (theoretical quantum efficiency of 200\%). This luminescence phenomenon has been reported for quantum dots (multiple exciton generation), ${ }^{1,2}$ dye molecules (singlet fission), ${ }^{3}$ and couples of $\mathrm{RE}^{3+}$ ions (downconversion). ${ }^{4}$ Recently, many examples of downconversion through ET have been reported for a variety of combinations of $\mathrm{RE}^{3+}$ ions. ${ }^{4,5}$ The search for downconversion materials was initially driven by the need for more efficient phosphors in lighting and displays and more recently by the potential application in photovoltaics. ${ }^{6-8}$ Converting one high-energy (UV and blue) photon into two IR photons above the c-Si band gap gives rise to current (and thus efficiency) doubling for the high-energy part of the solar spectrum. ${ }^{9}$ Even though downconversion has been explored and demonstrated for a variety of materials, downconversion materials are still far from practical application. The most efficient downconversion is realized in $\mathrm{RE}^{3+}$-doped materials. Unfortunately, absorption of the solar spectrum is inefficient due to the intrinsic low absorption cross section (on the order of $10^{-21} \mathrm{~cm}^{2}$ ) of $\mathrm{RE}^{3+}$ ions (intraconfigurational parity forbidden $4 \mathrm{f}^{\mathrm{n}}-4 \mathrm{f}^{\mathrm{n}}$ transitions) and the discrete sharp absorption lines covering only a small part of the solar spectrum. As a result, only a fraction of the solar spectrum can be harvested by conventional downconversion materials.

To improve the absorption and the response to the solar spectrum, there is a worldwide search for broadband sensitizers with high absorption cross sections. So far, especially $\mathrm{Ce}^{3+}$ and $\mathrm{Eu}^{2+}$ have been explored as sensitizers but with limited success. ${ }^{10,11}$ For the efficient $\mathrm{Pr}^{3+}-\mathrm{Yb}^{3+}$ downconversion couple, incorporation of $\mathrm{Ce}^{3+}$ and $\mathrm{Eu}^{2+}$ as sensitizers unfortunately leads to quenching of the excited $4 \mathrm{f}^{\mathrm{n}-1} 5 \mathrm{~d}$ state of the sensitizers via metal-to-metal charge-transfer states involving nearby $\mathrm{Yb}^{3+}$ or $\mathrm{Pr}^{3+}$ ions. ${ }^{12,13}$ An alternative option is to use organic dye that was first demonstrated to sensitize IR emission in RE-doped NCs. ${ }^{14}$ The use of NCs is crucial. Efficient ET from dyes (donor, D) to RE ions (acceptor, A) requires a small D-A distance $R$ as the probability for FRET scales with $R^{-6}$. A close proximity can be realized by absorbing dye molecules at the surface of RE-doped NCs where a significant fraction of RE ions is close to the surface. Later, the same principle was successfully applied in using dyesensitization to enhance the efficiency for upconversion luminescence in NCs. ${ }^{15}$ This pioneering work triggered research to further increase the upconversion efficiency. ${ }^{16-20}$ Surprisingly, the concept of dye-sensitized downconversion has so far not been reported. In the present study, we investigate dye-sensitized downconversion for a combination of a blue/ UV-absorbing Coumarin dye and $\mathrm{Pr}^{3+}, \mathrm{Yb}^{3+}$ co-doped $\mathrm{NaYF}_{4}$ NCs. Absorption of the Coumarin dye on $\mathrm{NaYF}_{4}: \mathrm{Pr}, \mathrm{Yb} \mathrm{NCs}$ results in a significant (30-fold) enhancement of $\mathrm{Yb}^{3+} \mathrm{IR}$ emission. This strategy of dye-sensitization can be exploited to enhance the downconversion efficiency for a wide range of lanthanide-doped materials and improve the efficiency of solar cells.

The $\beta-\mathrm{NaYF}_{4}: 1 \% \mathrm{Pr}^{3+} 20 \% \mathrm{Yb}^{3+} \mathrm{NCs}$ were synthesized using well-established colloidal synthesis techniques. ${ }^{21}$ (See the Supporting Information, SI.) Originally, the ligand on NC surface is oleate (hydrophobic surface). A two-step ligand exchange is employed to realize the dye-sensitization, as illustrated in Figure 1a. First, the oleate ligands are exchanged with ionic nitrosonium tetrafluoroborate $\left(\mathrm{NOBF}_{4}\right){ }^{22}$ stabilizing the NCs (hydrophilic surface) in polar solvents, such as $N, N$ dimethylformamide (DMF) used in the present study. Next,

Received: February 16, 2018

Accepted: March 9, 2018

Published: March 9, 2018 


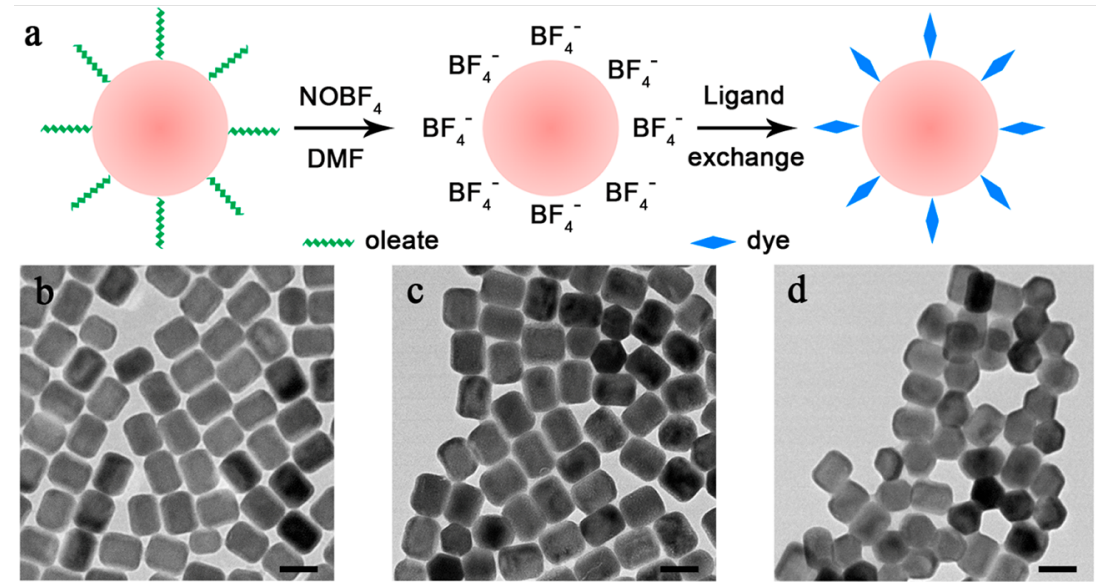

Figure 1. (a) Schematic diagram of ligand exchange for the dye-sensitized NCs. TEM images of $\left.\mathrm{NaYF}_{4}: 1 \% \mathrm{Pr}^{3+} 20 \% \mathrm{Yb}^{3+} \mathrm{NCs}^{(b)}\right) \mathrm{NOBF}_{4} \mathrm{modified}$ NCs (c), and dye-sensitized NCs (d). Scale bar $=50 \mathrm{~nm}$.
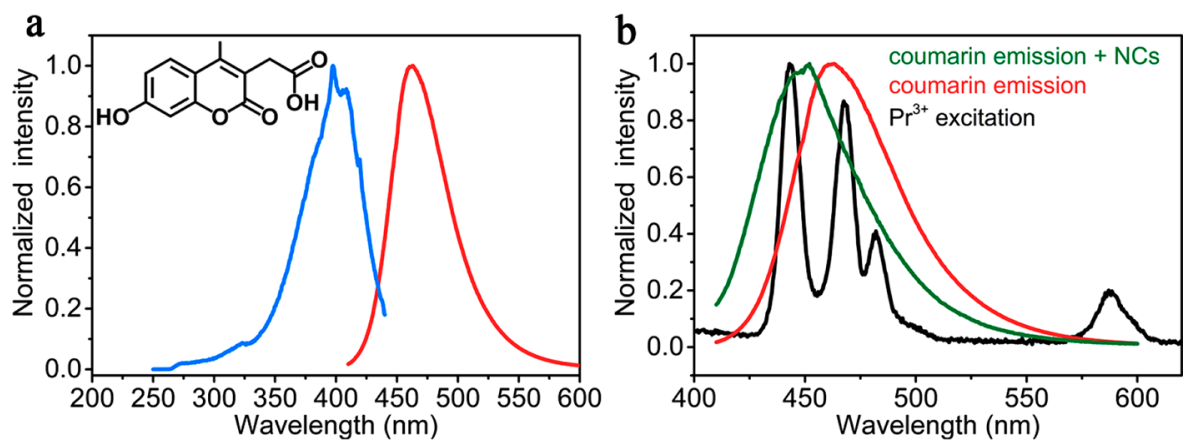

Figure 2. (a) Excitation (blue, $\lambda_{\mathrm{em}}=462 \mathrm{~nm}$ ) and emission (red, $\left.\lambda_{\mathrm{ex}}=397 \mathrm{~nm}\right)$ spectra of Coumarin $(5 \mu \mathrm{g} / \mathrm{mL})$ in DMF. The inset shows the molecular structure of Coumarin. (b) Excitation (black, $\lambda_{\mathrm{em}}=980 \mathrm{~nm}$ ) spectrum of $\mathrm{NaYF}_{4}: 1 \% \mathrm{Pr}^{3+} 20 \% \mathrm{Yb}^{3+} \mathrm{NCs}$ and emission $\left(\lambda_{\mathrm{ex}}=397 \mathrm{~nm}\right)$ spectra of Coumarin (red: the same red line as in panel a; green: $0.5 \mathrm{mg} / \mathrm{mL} \mathrm{NaYF} 4: 1 \% \mathrm{Pr}^{3+} 20 \% \mathrm{Yb}^{3+} \mathrm{NCs}$ with $0.025 \mu \mathrm{g} / \mathrm{mL} \mathrm{Coumarin}$ in DMF).
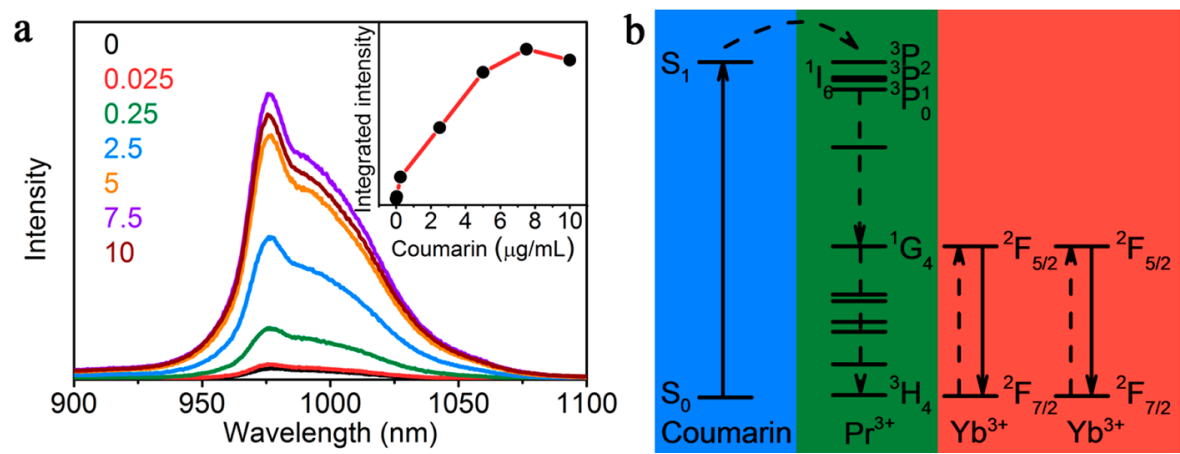

Figure 3. (a) Emission spectra of $0.5 \mathrm{mg} / \mathrm{mL} \mathrm{NaYF}_{4}: 1 \% \mathrm{Pr}^{3+} 20 \% \mathrm{Yb}^{3+} \mathrm{NCs}$ without Coumarin $\left(\lambda_{\text {ex }}=443 \mathrm{~nm}\right)$ and with different Coumarin concentrations $\left(0.025\right.$ to $10 \mu \mathrm{g} / \mathrm{mL}, \lambda_{\mathrm{ex}}=397 \mathrm{~nm}$ ). The inset shows the integrated intensity of $\mathrm{Yb}^{3+}$ emission as a function of Coumarin concentration. (b) Energy level diagram of Coumarin-sensitized downconversion in $\mathrm{Pr}^{3+}, \mathrm{Yb}^{3+}$ co-doped NCs.

the Coumarin dye dissolved in DMF is added, allowing the dyesensitization. Transmission electron microscopy (TEM) images in Figure $1 \mathrm{~b}-\mathrm{d}$ show the monodisperse NCs of $\sim 22 \times 55 \mathrm{~nm}$, both top and side views. The size is important to calculate the number of dye molecules per NC (vide infra).

The commercially available 7-hydroxy-4-methyl-3-coumarinylacetic acid is chosen as dye molecule. Coumarin molecules can bind to the NC surface via electrostatic attraction of carboxylic groups and surface $\mathrm{RE}^{3+}$ ions. (See molecular structure as inset in Figure 2a.) Figure 2a shows the emission (red) and excitation (blue) spectra for Coumarin in DMF. The emission band has a maximum at $462 \mathrm{~nm}$. A blue shift is observed for the Coumarin emission after the addition of NCs (compare the green and red lines in Figure 2b), implying the binding of Coumarin on NC surface. A similar blue shift of dye emission after dye binding to $\mathrm{NaYF}_{4} \mathrm{NCs}$ was also reported in ref 15 . The excitation spectrum of Coumarin spans a broad spectral region $(320-450 \mathrm{~nm})$ with a maximum around 400 $\mathrm{nm}$. Figure $2 \mathrm{~b}$ shows the excitation spectrum of $\mathrm{Yb}^{3+}$ emission for $\mathrm{NaYF}_{4}: 1 \% \mathrm{Pr}^{3+} 20 \% \mathrm{Yb}^{3+} \mathrm{NCs}$ (black). Excitation lines are observed around 443,467, 482, and $587 \mathrm{~nm}$, attributed to transitions of $\mathrm{Pr}^{3+}$ from the ${ }^{3} \mathrm{H}_{4}$ ground state to the ${ }^{3} \mathrm{P}_{2},{ }^{3} \mathrm{P}_{1},{ }^{1} \mathrm{I}_{6}$, ${ }^{3} \mathrm{P}_{0}$, and ${ }^{1} \mathrm{D}_{2}$ excited states. ${ }^{8}$ There is a good spectral overlap between the Coumarin emission and the ${ }^{1} \mathrm{I}_{6}$ and ${ }^{3} \mathrm{P}_{J}$ absorption 

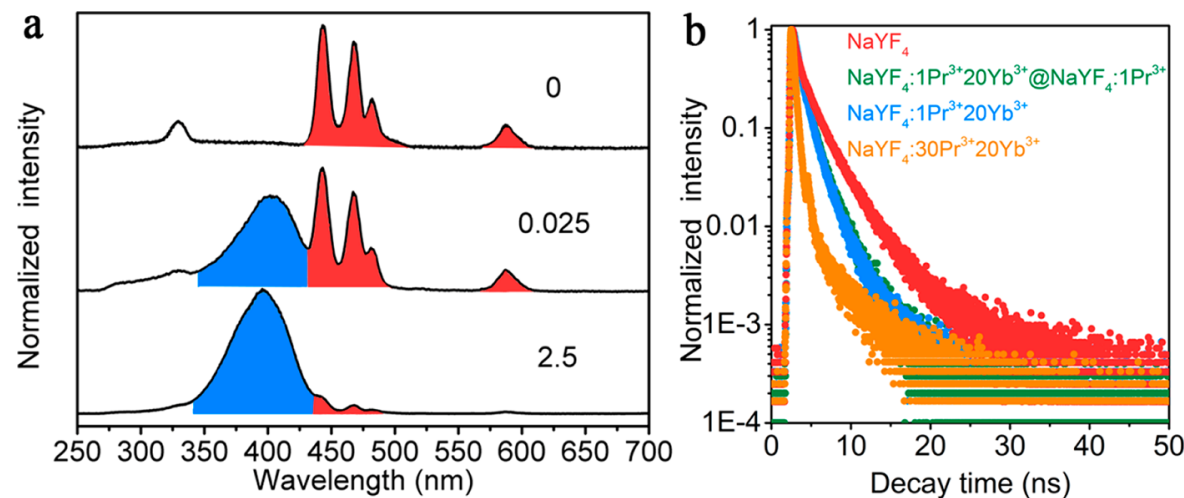

Figure 4. (a) Excitation spectra monitoring $980 \mathrm{~nm} \mathrm{Yb}{ }^{3+}$ emission for $0.5 \mathrm{mg} / \mathrm{mL} \mathrm{NaYF} 4: 1 \% \mathrm{Pr}^{3+} 20 \% \mathrm{Yb}^{3+} \mathrm{NCs}$ with $0,0.025$, and $2.5 \mu \mathrm{g} / \mathrm{mL}$ Coumarin in DMF. (b) Luminescence decay curves for Coumarin emission (excited by a $405 \mathrm{~nm}$ ps pulsed diode laser) for a $7.5 \mu \mathrm{g} / \mathrm{mL}$ Coumarin solution in the presence of $\mathrm{NaYF}_{4} \mathrm{NCs}$ (red), $\mathrm{NaYF}_{4}: 1 \% \mathrm{Pr}^{3+} 20 \% \mathrm{Yb}^{3+} @ \mathrm{NaYF}_{4}: 1 \% \mathrm{Pr}^{3+}$ core-shell NCs (green), $\mathrm{NaYF}_{4}: 1 \% \mathrm{Pr}^{3+} 20 \% \mathrm{Yb}^{3+} \mathrm{NCs}^{3}$ (blue), and $\mathrm{NaYF}_{4}: 30 \% \mathrm{Pr}^{3+} 20 \% \mathrm{Yb}^{3+} \mathrm{NCs}$ (orange).

lines of $\mathrm{Pr}^{3+}$, which indicates that efficient ET from Coumarin to $\mathrm{Pr}^{3+}$ is possible. ${ }^{23}$ The hybrid NCs consisting of organic Coumarin molecules absorbed at the inorganic nanomaterial surface can efficiently absorb and downconvert the blue and UV spectral region in the solar spectrum. ${ }^{24}$ The strong spectral overlap of Coumarin emission and $\mathrm{Pr}^{3+}$ absorption and the large absorption spectral width with high molar extinction coefficient $\left(19000 \mathrm{M}^{-1} \mathrm{~cm}^{-1} \text { in the absorption maximum }\right)^{25}$ make Coumarin a highly promising dye to sensitize downconversion.

To investigate the occurrence and efficiency of dye-sensitized downconversion in the Coumarin@ $\mathrm{NaYF}_{4}: \mathrm{Pr}, \mathrm{Yb} \mathrm{NC}$ system, $\mathrm{Yb}^{3+}$ emission spectra were measured for dispersions of $\mathrm{NaYF}_{4}: 1 \% \operatorname{Pr} 20 \% \mathrm{Yb}$ NCs with different concentrations of Coumarin. In Figure 3a, emission spectra are shown in the IR spectral region between 900 and $1100 \mathrm{~nm}$ for excitation at $397 \mathrm{~nm}$, in the maximum of Coumarin absorption band. For comparison, the emission spectrum for NCs without Coumarin is shown (under excitation in the strongest $4 \mathrm{f}-4 \mathrm{f}$ excitation line at $443 \mathrm{~nm}$ ). All spectra were measured under identical conditions such that absolute emission intensities can be compared. The IR emission intensity strongly increases with increasing Coumarin concentration until the optimal concentration of $7.5 \mu \mathrm{g} / \mathrm{mL}$. This enhancement of IR emission is due to the increased absorption of $397 \mathrm{~nm}$ excitation light as Coumarin concentration increases. A further increase in the concentration induces self-quenching of Coumarin, leading to an overall drop of the emission intensity. The inset in Figure 3a depicts the trend of integrated emission intensity versus Coumarin concentration. Quantitative analysis reveals a 30fold enhancement for $\mathrm{Yb}^{3+}$ emission in comparison with $4 \mathrm{f}-4 \mathrm{f}$ excitation in the ${ }^{3} \mathrm{P}_{2}$ level of $\mathrm{Pr}^{3+}$. The results provide clear evidence that the strategy of the dye-sensitized downconversion works. It is interesting to estimate the number of dye molecule and intermolecular distance. For the optimum $7.5 \mu \mathrm{g} / \mathrm{mL}$ Coumarin concentration (see the SI), the molecule number is estimated to be 1080 per NC with an intermolecular distance of $\sim 3.0 \mathrm{~nm}$. This distance is similar to those found for the optimum dye concentrations of dye-sensitized upconversion in the literatures $(\sim 3.4 \mathrm{~nm}$ in ref 15 and $\sim 3 \mathrm{~nm}$ in ref 19$)$.

The dye-sensitized downconversion involves two ET steps, as shown in Figure 3b. After absorbing UV radiation, the excited Coumarin molecules nonradiatively transfer the energy to the ${ }^{3} \mathrm{P}_{J}$ and ${ }^{1} \mathrm{I}_{6}$ states of nearby $\operatorname{Pr}^{3+}$ ions. Because the separation between Coumarin at the surface and $\operatorname{Pr}^{3+}$ ions in the NC surface layer is relatively large, the dipole-dipole FRET dominates the dye-sensitization. ${ }^{15,26,27}$ Dexter ET via exchange interaction is not expected over the NC interface because this type of ET relies on wave function overlap and only occurs over distances up to $0.5 \AA^{28}$ After Coumarin to $\operatorname{Pr}^{3+}$ ET, fast relaxation to the ${ }^{3} \mathrm{P}_{0}$ state of $\mathrm{Pr}^{3+}$ is followed by the second ET process that involves a resonant two-step ET to two neighboring $\mathrm{Yb}^{3+}$ ions through $\operatorname{Pr}^{3+}\left({ }^{3} \mathrm{P}_{0}-{ }^{1} \mathrm{G}_{4}\right) \rightarrow \mathrm{Yb}^{3+}$ $\left({ }^{2} \mathrm{~F}_{7 / 2}-{ }^{2} \mathrm{~F}_{5 / 2}\right)$ and $\operatorname{Pr}^{3+}\left({ }^{1} \mathrm{G}_{4}-{ }^{3} \mathrm{H}_{4}\right) \rightarrow \mathrm{Yb}^{3+}$ $\left({ }^{2} \mathrm{~F}_{7 / 2}-{ }^{2} \mathrm{~F}_{5 / 2}\right) .{ }^{6,8,29,30}$ The excited $\mathrm{Yb}^{3+}$ ions emit IR radiation with a theoretical quantum efficiency of $200 \%$. On the basis of previous work, the efficiency of this downconversion process is high, as determined from a comparison of absorption and excitation spectra. ${ }^{8}$ More recently, direct evidence of downconversion has been obtained through correlated photon counting experiments. ${ }^{31}$

To provide further evidence of dye-sensitized downconversion, we measured the excitation spectra (Figure 4a) of the $980 \mathrm{~nm} \mathrm{Yb}^{3+}$ emission for $\mathrm{NaYF}_{4}: \mathrm{Pr}, \mathrm{Yb} \mathrm{NC}$ dispersions with different concentrations of Coumarin. In the absence of Coumarin, the excitation spectrum only shows excitation lines from $\operatorname{Pr}^{3+} \mathrm{f}-\mathrm{f}{ }^{3} \mathrm{H}_{4} \rightarrow{ }^{3} \mathrm{P}_{0,1,2},{ }^{1} \mathrm{I}_{6},{ }^{1} \mathrm{D}_{2}$ transitions (red area in Figure $4 \mathrm{a}$ ). After the addition of Coumarin, the dyesensitization occurs and the broad Coumarin excitation band between 320 and $450 \mathrm{~nm}$ (blue area) appears. Already for the lowest Coumarin concentration $(0.025 \mu \mathrm{g} / \mathrm{mL})$, the relative intensities for Coumarin excitation band and $\mathrm{Pr}^{3+}$ excitation lines are similar. The relative intensity of Coumarin excitation band rapidly increases with Coumarin concentration and dominates the excitation spectrum for a concentration of 2.5 $\mu \mathrm{g} / \mathrm{mL}$, confirming the high efficiency gain for dye-sensitized downconversion. The stability of the NC-dye complex was evaluated by measuring NIR emission spectra under continuous UV-A excitation. In the first hour a $\sim 40 \%$ intensity decrease is observed, possibly because of photoinduced desorption of dye molecules (Figure S2). For longer times the signal stabilizes.

Insight into the mechanism and efficiency of the Coumarin to $\operatorname{Pr}^{3+}$ ET can be gained from luminescence decay curves of Coumarin emission. These were measured for Coumarin coupled to four different types of $\mathrm{NaYF}_{4} \mathrm{NCs}$ (Figure $4 \mathrm{~b}$, all for the Coumarin concentration of $7.5 \mu \mathrm{g} / \mathrm{mL}$ ). The decay is nonexponential and is characterized by average lifetime $\tau_{\text {avg }}=$ $\sum_{0}^{t} t I(t) / \sum_{0}^{t} I(t)$, where $I(t)$ is the emission intensity at time 
$t^{32}$ As a reference, the luminescence decay for Coumarin bound to undoped $\mathrm{NaYF}_{4} \mathrm{NCs}$ was measured (red) with $\tau_{\text {avg }}=$ 4.73 ns. The Coumarin emission in the presence of $\mathrm{NaYF}_{4}: 1 \%$ $\mathrm{Pr}^{3+} 20 \% \mathrm{Yb}^{3+}$ NCs (blue) shows a faster decay with a $\tau_{\text {avg }}$ of $3.78 \mathrm{~ns}$, indicating that FRET from Coumarin to $\mathrm{Pr}^{3+}$ occurs and reduces the lifetime by introducing an extra decay channel through FRET. Note that in the case of radiative ET no shortening of luminescence lifetime is expected and the observation of a shorter Coumarin emission lifetime for $\mathrm{Pr}^{3+}$ doped NCs is a direct evidence of nonradiative ET. In addition, luminescence decay curves were investigated for $\mathrm{NaYF}_{4}: 1 \%$ $\mathrm{Pr}^{3+} 20 \% \mathrm{Yb}^{3+} @ \mathrm{NaYF}_{4}: 1 \% \mathrm{Pr}^{3+}$ core-shell NCs (green) to study the influence of an $\mathrm{Yb}$-free shell on the $\mathrm{Yb}^{3+}$ emission efficiency, while also the Coumarin decay curve was measured to confirm that the faster decay in the $\mathrm{Pr}, \mathrm{Yb}$ co-doped NCs is caused by ET to $\mathrm{Pr}^{3+}$ and not $\mathrm{Yb}^{3+}$. The $\mathrm{Yb}$-free shell around the core NCs results in a longer $\tau_{\text {avg }}$ for $\mathrm{Yb}^{3+}$ emission (44.2 $\mu \mathrm{s}$ for core-shell vs $21.7 \mu$ s for core, Figure S1) and stronger $\mathrm{Yb}^{3+}$ emission. The beneficial influence of $\mathrm{Yb}$-free shell can be explained by a reduction in surface quenching of the $\mathrm{Yb}^{3+}$ emission by surface-related defects and multiphonon relaxation by high-energy vibrations of surface-bound ligand and solvent. The Coumarin emission decay time does not change for coreshell NCs $\left(\tau_{\text {avg }}=3.83 \mathrm{~ns}\right.$, very similar to $3.78 \mathrm{~ns}$ measured for Coumarin-sensitized core NCs with the same $1 \% \operatorname{Pr}^{3+}$ doping concentration in the shell). This confirms that the shortening of decay time is caused by Coumarin to $\operatorname{Pr}^{3+}$ FRET. The surface passivation can be a strategy to obtain enhanced downconversion emission. For the low (1\%) $\mathrm{Pr}^{3+}$ concentration in the shell or core, the FRET probability is relatively low. More efficient FRET is expected for higher $\mathrm{Pr}^{3+}$ concentrations. In Figure $4 \mathrm{~b}$, the decay curve of Coumarin emission in the presence of $\mathrm{NaYF}_{4}: 30 \% \mathrm{Pr}^{3+} 20 \% \mathrm{Yb}^{3+} \mathrm{NCs}$ (orange) is shown. As a consequence of a higher $\operatorname{Pr}^{3+}$ concentration, a faster decay of $3.18 \mathrm{~ns}$ is observed, reflecting a higher FRET efficiency. Despite the higher FRET probability, the intensity of the downconversion luminescence does not increase because crossrelaxation quenching of ${ }^{3} \mathrm{P}_{0}$ state of $\mathrm{Pr}^{3+}$ is very efficient at elevated $\operatorname{Pr}^{3+}$ concentrations. ${ }^{33,34}$

The present experiments have demonstrated the feasibility of dye-sensitized downconversion. Further research will be aimed at enhancing the FRET and downconversion efficiency by optimization of $\mathrm{RE}^{3+}$ concentrations and synthesis conditions and through more complex core-shell architectures. Optimization of the downconversion efficiency can be realized by varying the $\operatorname{Pr}^{3+}$ and $\mathrm{Yb}^{3+}$ concentrations and by reducing multiphonon quenching of the $\mathrm{Yb}^{3+}$ emission by nearby highenergy $\mathrm{C}-\mathrm{H}$ and $\mathrm{O}-\mathrm{H}$ vibrations (e.g., by using $\mathrm{C}-\mathrm{H}$ and $\mathrm{O}-$ $\mathrm{H}$ free solvents) and can be verified by IR quantum yield measurements. For practical applications, the photostability of the dye is also important. Inorganic NCs have a high photostability, but dye molecules suffer from photodegradation. Coumarin dyes are known for their relatively high stability. The stability depends on the solvent and can be enhanced by structural modifications of the Coumarin. ${ }^{35}$ Efficiency enhancement in more complex architectures may involve an intermediate sensitizer as $\mathrm{Tb}^{3+}$, which can be introduced in high concentration in a $\mathrm{NaYF}_{4}: \mathrm{Tb}^{3+}$ shell surrounding the $\mathrm{NaYF}_{4}: \mathrm{Pr}^{3+} \mathrm{Yb}^{3+}$ core. The ${ }^{5} \mathrm{D}_{4}$ level of $\mathrm{Tb}^{3+}$ is situated just above the ${ }^{3} \mathrm{P}_{0}$ level of $\operatorname{Pr}^{3+}$. Because the ${ }^{5} \mathrm{D}_{4}$ emission from $\mathrm{Tb}^{3+}$ does not suffer from cross-relaxation quenching, a high $\mathrm{Tb}^{3+}$ concentration can be incorporated in the outer shell, allowing efficient dye- $\mathrm{Tb}^{3+}$ FRET, followed by $\mathrm{Tb}^{3+}-\mathrm{Pr}^{3+}$ ET and
$\mathrm{Pr}^{3+}-\mathrm{Yb}^{3+}$ downconversion. Also, alternative dyes may be used besides Coumarin and show more efficient absorption, higher stability, or enhanced ET to $\mathrm{RE}^{3+}$ acceptors in the downconversion NCs.

In summary, dye-sensitized downconversion has been realized by a combination of organic Coumarin dye molecules and inorganic $\mathrm{NaYF}_{4}: \mathrm{Pr}^{3+} \mathrm{Yb}^{3+}$ NCs. The favorable spectral overlap between Coumarin emission and $\mathrm{Pr}^{3+}$ absorption gives rise to efficient Coumarin- $\mathrm{Pr}^{3+}$ FRET, which sensitizes the $\mathrm{Pr}-\mathrm{Yb}$ downconversion couple. Because of the high-absorption cross section of Coumarin, the dye-sensitization enhances the downconversion emission intensity by more than an order of magnitude and extends the spectral range that can be utilized for spectral conversion from several sharp lines between 450 and $500 \mathrm{~nm}$ to a wide spectral range spanning the blue and near-UV region. Further optimization of synthesis conditions and dopant concentrations and using core-shell architectures with directional ET can further improve the FRET and downconversion efficiency. The presently reported dyesensitized downconversion can be applied to other lanthanide-doped downconversion nanomaterials and serves as a stepping stone for application of downconversion materials in photovoltaic devices.

\section{ASSOCIATED CONTENT}

\section{Supporting Information}

The Supporting Information is available free of charge on the ACS Publications website at DOI: 10.1021/acs.jpclett.8b00516.

Experimental methods, TEM image, luminescence decay curves, and IR emission spectra during UV irradiation. (PDF)

\section{AUTHOR INFORMATION}

\section{Corresponding Author}

*E-mail: A.Meijerink@uu.nl.

ORCID 1

Andries Meijerink: 0000-0003-3573-9289

Notes

The authors declare no competing financial interest.

\section{ACKNOWLEDGMENTS}

This work was financially supported by the China Scholarship Council (no. 201506380101).

\section{REFERENCES}

(1) Kagan, C. R.; Lifshitz, E.; Sargent, E. H.; Talapin, D. V. Building Devices from Colloidal Quantum Dots. Science 2016, 353, aac5523.

(2) McGuire, J. A.; Sykora, M.; Joo, J.; Pietryga, J. M.; Klimov, V. I. Apparent Versus True Carrier Multiplication Yields in Semiconductor Nanocrystals. Nano Lett. 2010, 10, 2049-2057.

(3) Smith, M. B.; Michl, J. Singlet Fission. Chem. Rev. 2010, 110, 6891-6936.

(4) Huang, X. Y.; Han, S. Y.; Huang, W.; Liu, X. G. Enhancing Solar Cell Efficiency: the Search for Luminescent Materials as Spectral Converters. Chem. Soc. Rev. 2013, 42, 173-201.

(5) Wegh, R. T.; Donker, H.; Oskam, K. D.; Meijerink, A. Visible Quantum Cutting in $\mathrm{LiGdF}_{4}: \mathrm{Eu}^{3+}$ through Downconversion. Science 1999, 283, 663-666.

(6) Zhang, Q. Y.; Huang, X. Y. Recent Progress in Quantum Cutting Phosphors. Prog. Mater. Sci. 2010, 55, 353-427.

(7) Timmerman, D.; Izeddin, I.; Stallinga, P.; Yassievich, I. N.; Gregorkiewicz, T. Space-Separated Quantum Cutting with Silicon 
Nanocrystals for Photovoltaic Applications. Nat. Photonics 2008, 2, 105-109.

(8) van der Ende, B. M.; Aarts, L.; Meijerink, A. Near-Infrared Quantum Cutting for Photovoltaics. Adv. Mater. 2009, 21, 30733077.

(9) de la Mora, M. B.; Amelines-Sarria, O.; Monroy, B. M.; Hernández-Pérez, C. D.; Lugo, J. E. Materials for Downconversion in Solar Cells: Perspectives and Challenges. Sol. Energy Mater. Sol. Cells 2017, 165, 59-71.

(10) Sun, T. Y.; Chen, X.; Jin, L. M.; Li, H.-W.; Chen, B.; Fan, B.; Moine, B.; Qiao, X.; Fan, X. P.; Tsang, S.-W.; Yu, S. F.; Wang, F. Broadband Ce(III)-Sensitized Quantum Cutting in Core-Shell Nanoparticles: Mechanistic Investigation and Photovoltaic Application. J. Phys. Chem. Lett. 2017, 8, 5099-5104.

(11) Zhou, J. J.; Zhuang, Y. X.; Ye, S.; Teng, Y.; Lin, G.; Zhu, B.; Xie, J. H.; Qiu, J. R. Broadband Downconversion Based Infrared Quantum Cutting by Cooperative Energy Transfer from $\mathrm{Eu}^{2+}$ to $\mathrm{Yb}^{3+}$ in Glasses. Appl. Phys. Lett. 2009, 95, 141101.

(12) Yu, D. C.; Rabouw, F. T.; Boon, W. Q.; Kieboom, T.; Ye, S.; Zhang, Q. Y.; Meijerink, A. Insights Into the Energy Transfer Mechanism in $\mathrm{Ce}^{3+}-\mathrm{Yb}^{3+}$ Codoped YAG Phosphors. Phys. Rev. B: Condens. Matter Mater. Phys. 2014, 90, 165126.

(13) Ueda, J.; Tanabe, S. Visible to Near Infrared Conversion in $\mathrm{Ce}^{3+}-\mathrm{Yb}^{3+}$ Co-Doped YAG Ceramics. J. Appl. Phys. 2009, 106, 043101 .

(14) Zhang, J.; Shade, C. M.; Chengelis, D. A.; Petoud, S. A Strategy to Protect and Sensitize Near-Infrared Luminescent $\mathrm{Nd}^{3+}$ and $\mathrm{Yb}^{3+}$ : Organic Tropolonate Ligands for the Sensitization of $\mathrm{Ln}^{3+}$-Doped $\mathrm{NaYF}_{4}$ Nanocrystals. J. Am. Chem. Soc. 2007, 129, 14834-14835.

(15) Zou, W. Q.; Visser, C.; Maduro, J. A.; Pshenichnikov, M. S.; Hummelen, J. C. Broadband Dye-Sensitized Upconversion of NearInfrared Light. Nat. Photonics 2012, 6, 560-564.

(16) Wang, X. D.; Valiev, R. R.; Ohulchanskyy, T. Y.; Ågren, H.; Yang, C. H.; Chen, G. Y. Dye-Sensitized Lanthanide-Doped Upconversion Nanoparticles. Chem. Soc. Rev. 2017, 46, 4150-4167.

(17) Wei, W.; Chen, G. Y.; Baev, A.; He, G. S.; Shao, W.; Damasco, J.; Prasad, P. N. Alleviating Luminescence Concentration Quenching in Upconversion Nanoparticles through Organic Dye Sensitization. J. Am. Chem. Soc. 2016, 138, 15130-15133.

(18) Lee, J.; Yoo, B.; Lee, H.; Cha, G. D.; Lee, H.-S.; Cho, Y.; Kim, S. Y.; Seo, H.; Lee, W.; Son, D.; Kang, M.; Kim, H. M.; Park, Y. Il; Hyeon, T.; Kim, D.-H. Ultra-Wideband Multi-Dye-Sensitized Upconverting Nanoparticles for Information Security Application. Adv. Mater. 2017, 29, 1603169.

(19) Chen, G. Y.; Damasco, J.; Qiu, H. L.; Shao, W.; Ohulchanskyy, T. Y.; Valiev, R. R.; Wu, X.; Han, G.; Wang, Y.; Yang, C. H.; Ågren, H.; Prasad, P. N. Energy-Cascaded Upconversion in an Organic DyeSensitized Core/Shell Fluoride Nanocrystal. Nano Lett. 2015, 15, $7400-7407$.

(20) Wu, X.; Zhang, Y. W.; Takle, K.; Bilsel, O.; Li, Z. J.; Lee, H.; Zhang, Z. J.; Li, D. S.; Fan, W.; Duan, C. Y.; Chan, E. M.; Lois, C.; Xiang, Y.; Han, G. Dye-Sensitized Core/Active Shell Upconversion Nanoparticles for Optogenetics and Bioimaging Applications. ACS Nano 2016, 10, 1060-1066.

(21) Wang, F.; Deng, R. R.; Liu, X. G. Preparation of Core-Shell $\mathrm{NaGdF}_{4}$ Nanoparticles Doped with Luminescent Lanthanide Ions to be Used as Upconversion-Based Probes. Nat. Protoc. 2014, 9, 16341644.

(22) Dong, A. G.; Ye, X. C.; Chen, J.; Kang, Y. J.; Gordon, T.; Kikkawa, J. M.; Murray, C. B. A Generalized Ligand-Exchange Strategy Enabling Sequential Surface Functionalization of Colloidal Nanocrystals. J. Am. Chem. Soc. 2011, 133, 998-1006.

(23) Förster, T. Zwischenmolekulare Energiewanderung und Fluoreszenz. Ann. Phys. 1948, 437, 55-75.

(24) Richards, B. S. Luminescent Layers for Enhanced Silicon Solar Cell Performance: Down-Conversion. Sol. Energy Mater. Sol. Cells 2006, 90, 1189-1207.

(25) Sabnis, R. W. Handbook of Fluorescent Dyes and Probes; John Wiley \& Sons: Hoboken, NJ, 2015.
(26) Agbo, P.; Abergel, R. J. Ligand-Sensitized Lanthanide Nanocrystals: Merging Solid-State Photophysics and Molecular Solution Chemistry. Inorg. Chem. 2016, 55, 9973-9980.

(27) Chen, G. Y.; Shao, W.; Valiev, R. R.; Ohulchanskyy, T. Y.; He, G. S.; Ågren, H.; Prasad, P. N. Efficient Broadband Upconversion of Near-Infrared Light in Dye-Sensitized Core/Shell Nanocrystals. Adv. Opt. Mater. 2016, 4, 1760-1766.

(28) Dexter, D. L. A Theory of Sensitized Luminescence in Solids. J. Chem. Phys. 1953, 21, 836-850.

(29) Katayama, Y.; Tanabe, S. Near Infrared Downconversion in $\mathrm{Pr}^{3+}-\mathrm{Yb}^{3+}$ Codoped Oxyfluoride Glass Ceramics. Opt. Mater. 2010, 33, 176-179.

(30) Zhu, W. J.; Chen, D. Q.; Lei, L.; Xu, J.; Wang, Y. S. An ActiveCore/Active-Shell Structure with Enhanced Quantum-Cutting Luminescence in $\mathrm{Pr}-\mathrm{Yb} \mathrm{Co}$-Doped Monodisperse Nanoparticles. Nanoscale 2014, 6, 10500-10504.

(31) de Jong, M.; Meijerink, A.; Rabouw, F. T. Non-Poissonian Photon Statistics from Macroscopic Photon Cutting Materials. Nat. Commun. 2017, 8, 15537.

(32) Wang, Z. J.; Senden, T.; Meijerink, A. Photonic Effects for Magnetic Dipole Transitions. J. Phys. Chem. Lett. 2017, 8, 5689-5694.

(33) Naccache, R.; Vetrone, F.; Speghini, A.; Bettinelli, M.; Capobianco, J. A. Cross-Relaxation and Upconversion Processes in $\mathrm{Pr}^{3+}$ Singly Doped and $\mathrm{Pr}^{3+} / \mathrm{Yb}^{3+}$ Codoped Nanocrystalline $\mathrm{Gd}_{3} \mathrm{Ga}_{5} \mathrm{O}_{12}$ : the Sensitizer/Activator Relationship. J. Phys. Chem. C 2008, 112, 7750-7756.

(34) de Mello Donegá, C.; Meijerink, A.; Blasse, G. Non-Radiative Relaxation Processes of the $\operatorname{Pr}^{3+}$ Ion in Solids. J. Phys. Chem. Solids 1995, 56, 673-685.

(35) Jivaramonaikul, W.; Rashatasakhon, P.; Wanichwecharungruang, S. UVA Absorption and Photostability of Coumarins. Photochem. Photobiol. Sci. 2010, 9, 1120-1125. 